\title{
Effectiveness of the reserve option mechanism as a macroeconomic prudential tool: evidence from Turkey
}

\section{Afsin Sahin, Burak Dogan \& M. Hakan Berument}

To cite this article: Afsin Sahin, Burak Dogan \& M. Hakan Berument (2015) Effectiveness of the reserve option mechanism as a macroeconomic prudential tool: evidence from Turkey, Applied Economics, 47:56, 6075-6087, DOI: 10.1080/00036846.2015.1064077

To link to this article: http://dx.doi.org/10.1080/00036846.2015.1064077

曲 Published online: 30 Jun 2015.

Submit your article to this journal $\widetilde{ }$

Џلll Article views: 198

Q View related articles $\sqsubset$

View Crossmark data $\nearrow$

Citing articles: 1 View citing articles 


\title{
Effectiveness of the reserve option mechanism as a macroeconomic prudential tool: evidence from Turkey
}

\author{
Afsin Sahin $^{\mathrm{a}}$, Burak Dogan ${ }^{\mathrm{b}}$ and M. Hakan Berument ${ }^{\mathrm{c}, *}$ \\ ${ }^{a}$ Department of Banking, Gazi University, Ankara, 06500, Turkey \\ ${ }^{\mathrm{b}}$ Banking Regulation and Supervision Directorate, Central Bank of the \\ Turkish Republic of Northern Cyprus, Mersin, Turkey \\ ${ }^{\mathrm{c}}$ Department of Economics, Bilkent University, Ankara, 06800, Turkey
}

This article assesses the effectiveness of a novel macroprudential tool the reserve option mechanism (ROM) - which Turkey's central bank developed during the post-2008 period and has employed to control the risk associated with excessive capital flows. We assess how capital flows have affected economic variable changes since the introduction and usage of the ROM. Empirical evidence gathered from Turkey suggests that the tool decreases the effect of capital flow on capital flow (positive shock to capital flow dies out faster or becomes less persistent) and diminishes the effects of capital flow shocks on exchange and interest rates.

Keywords: macroeconomic prudential tools; reserve option mechanism; capital flows

JEL Classification: E58; E52; E42

\section{Introduction}

Following the 2008 financial crisis, central banks adopted various policy tools to address the challenges of the new economic environment. Most of these tools are considered macroprudential tools and might be seen as unconventional, with their use limited to extraordinary post-crisis periods. However, if they prove beneficial, these tools can still be used in stable conditions. Indeed, that crisis has shown that monetary and fiscal policies, on the one side, and micro and macro policy tools, on the other side, are not merely complementary but part of a complete toolbox to address the new economic environment. That is, if meaningful and rich, a sound policy set can be compiled such that each policy tool can be used whenever necessary. Blanchard et al. (2013) explain this concept as harmonizing a broad-scoped but instantly effective monetary policy and more-targeted fiscal measures (although their time lag limits the usefulness of the latter). The authors place macroprudential tools into three main categories: (1) tools to influence lender

*Corresponding author. E-mail: berument@bilkent.edu.tr The views expressed here do not necessarily represent the official position of the Central Bank of the TRNC. 
behaviour, i.e. capital requirements and leverage ratios; (2) tools to influence borrower behaviour, i.e. capping loan-to-value (LTV) ratios or debt-to-income (DTI) ratios; and (3) tools to influence both lender and borrower behaviours by capital flow management.

To the best of our knowledge, there is no single policy authority in the world that utilizes all of these categories of tools at the same time. There are two reasons for this. First, as is also mentioned by the IMF (2011), there are two prerequisite conditions (among others) to classifying any macro tool as macroprudential: (1) systemic risk should be targeted explicitly and specifically and (2) necessary governance arrangements should be ensured to synchronize all related institutions. Therefore, as the scope of macroprudential policies increases to cover the above three categories, it becomes harder to satisfy the prerequisite conditions. The second reason why all these tools are not used at the same time is that every economy needs a specific category of tools depending on the level of its financial and economic development. Working on macroprudential policies in 119 different countries between 2000 and 2013, Cerutti et al. (2015) claim that emerging economies mostly choose tools in the third category. Blanchard et al. (2013) elaborate this, suggesting that developing countries use macroprudential tools to affect foreign exchange while advanced countries use such tools to lead borrower behaviour.

There is also an increasing amount of empirical evidence on measuring the effectiveness of each category of macroprudential tools. Clerc et al. (2014) use a dynamic general equilibrium model that features the defaults of various borrower groups to measure the influence of the first category of macroprudential tools (such as capital requirements, countercyclical capital buffers and sectoral risk weights) on economic performance. Their results include three main inferences: (1) there is generally an optimal level of capital requirements; (2) the lower a bank's capital ratio (or the higher its leverage), the greater the scope for amplification of real and financial shocks; and (3) a moderate degree of countercyclical adjustments of capital requirements may significantly improve the benefits of setting these requirements at a high level. Claessens et al. (2014) track the effects of macroprudential policies between 2000 and 2010 in 48 countries and 2800 banks, and find that the second category of tools, i.e. setting caps on LTV and DTI ratios, significantly decreases credit growth (specifically foreign currency lending) and asset growth. Taking into account 13 Asian economies and 33 economies in other regions since 2000, Zhang and Zoli (2014) show that capital flow measures in the third category, such as broad limits on foreign currency borrowing, specific reserve requirements on foreign currency deposits or additional provisioning requirements on foreign exchange lending, help reduce housing price growth, equity flows, credit growth and bank leverage. (See Claessens (2014) and Galati and Moessner (2014) for an excellent, more-detailed theoretical discussion and literature review on the effectiveness of macroprudential tools.)

This article reports the effects of the reserve option mechanism (ROM), a tool developed by the Central Bank of the Republic of Turkey (CBRT) to cope with the country's excessive capital flows, which increased systematic risk in its macrobalances. $^{1}$ In particular, we assess how capital flows affect economic performance variables, such as exchange rate, interest rate, output and prices, and how these effects change with the different levels of ROM usage. The empirical evidence gathered in the article reveals that ROM usage decreases the effect of capital flows on exchange rate and interest rates as well as decreases the persistency of capital flow shocks.

\section{Understanding the ROM: rationale and purpose}

In the wake of the 2008 financial crisis, large foreign capital flows into Turkey, triggered by the expansionary monetary policies of the world's major central banks, have created a new kind of challenge for the CBRT. ${ }^{2}$ Capital flows have been forcing up the value of the Turkish Lira (TL) against foreign currency, increasing domestic liquidity and the credit supply of domestic banks to the private sector, and

\footnotetext{
${ }^{1}$ Alper et al. (2012, p. 7) write that the 'ROM essentially aims at reducing the detrimental effects of volatile capital flows on domestic markets by [bridging] the gap between [the] supply and demand of foreign currency'.

${ }^{2}$ From 2007 to 2013 , the M2 growth rates of the US, the UK and Japan was $29.27 \%, 20.40 \%$ and $14.39 \%$, respectively (Source: World Development Indicators).
} 
thus widening the current account deficit, accumulating risk. ${ }^{3}$ In response, the CBRT developed a tool to assist with its already-complex task: assuring financial stability. ${ }^{4}$

When the ROM was introduced, it was clearly stated that its purpose is the 'timely, controlled and effective provision of liquidity to the market in case of financial turmoil' (CBRT, 2011, p. 1). Thus, it was expected that the ROM would introduce a system that would work like a reservoir. During capital flow, ROM usage would rise (increases central bank reserves) and during capital outflow ROM usage would lower (decreases central bank reserves). However, financial turmoil in 2013 showed that the ROM did not function in this manner. At the same time, the motivation of the ROM is 'to help increase the resilience of the economy against external finance shocks and achieve financial stability' (IMF, 2011, p. 13). This mandate includes decreasing exchange rate fluctuation and credit expansion due to converting foreign exchange inflows into bank lending. The latter decreases the effect of capital inflows on aggregate demand. In other words, the ROM might work because capital flow will affect economic performance less. The given change (shock) to capital flow will thus affect the relevant macroeconomic variable less, which is the proposition that we test.

Conventional policy tools such as short-term interest rate may not deliver the desired outcomes in the new economic environment. Based on the challenges that have emerged since the 2008 financial crisis, the CBRT has defined financial stability as a goal supplementary to price stability and divided its policy tools into three categories: a direct credit policy, an interest rate policy and a liquidity policy (Kara, 2012). The first two policies were unremarkable; the direct credit policy aimed to reduce the level of banking credits through reserve requirements, and the interest rate policy set a short-term (weekly) funding rate rather than overnight rates. The essence of the new scheme was the liquidity policy, which comprised macro and micro tools, such as the interest rate corridor, a funding strategy and the ROM. ${ }^{5}$

The interest rate corridor, formed by locking the average CBRT funding rate between its overnight borrowing and lending rates, was the first tool introduced. Alper et al. (2012) note that this tool has directly affected economic agents' short-term portfolio decisions, which in turn have affected foreign exchange rate volatility. The funding strategy is designed to reflect the CBRT's perception of liquidity adequacy: the CBRT determines whether (1) funding will be via daily, weekly or monthly repos; (2) funding will be via market-maker banks' intermediation; or (3) whether there will be any funding at all. ${ }^{6}$ As with the interest rate corridor, this funding strategy can also affect economic agents' short-term portfolio decisions.

The ROM affects domestic banks' decisions about their balance sheets, allowing (though not obliging) banks to keep some ratio (called the reserve option ratio (ROR)) of their required TL reserves as foreign exchange (US dollars (USD)) and/or gold. The amount of USD and/or gold corresponding to the TL requirement is computed by multiplying the TL requirement with a reserve option coefficient (ROC) for each segment of the ROR. ${ }^{7}$ In this way, banks

${ }^{3}$ According to Yorukoglu and Cufadar (2008), during the years 2002-2007, following high amounts of capital inflows such as stocks, securities and money market instruments, the CBRT also started to accumulate foreign currency reserves. Between 2002 and 2007, the sum of yearly net foreign portfolio inflows as stocks (15 billion USD) and government securities (17.4 USD) was 32.4 billion USD, but had increased to 86.8 billion (30 billion as stocks and 56.7 billion as government securities) by 2014 (Source: CBRT EVDS, Balance of Payments Detailed Presentation).

${ }^{4}$ Please see Galati and Moessner (2014) for an excellent review of the literature on macroprudential policies and their effects on economic performance.

${ }^{5}$ See Başçı and Kara (2011) and Kara (2012) for detailed information on the new policy set-up. Mr Başçı is governor of the CBRT and Mr Kara is the director general of the CBRT's research department.

${ }^{6}$ Sometimes the CBRT does not hold its weekly repo auction. These instances are called 'exceptional days', and the CBRT does not fund the market on those days. Similarly, sometimes it announces 'short-term additional monetary tightening', which includes intra-day foreign exchange selling auctions plus market funding by the upper band of the interest rate corridor (on normal days the CBRT funds market-maker banks at the lower rate).

${ }^{7}$ The ROM practice of using the foreign exchange allowance instead of the TL began in September 2011, by setting the ROR as $10 \%$ and the ROC as 1 . Subsequently, the policy developed by defining different ROR segments and corresponding coefficients. As of October 2013, up to $60 \%$ of TL reserve requirements may be kept in foreign currency. The first $30 \%$ of the allowed foreign exchange partition is accepted by being multiplied by 1.4 . The coefficients for each subsequent $5 \%$ increase are $1.5,1.8,2.2,2.5$, 2.7 and 2.8, respectively. The gold option has a similar story. It began on the same date as the ROR and ROC, and as of October 2013 , up to $30 \%$ of TL reserve requirements can be kept as gold. The first $15 \%$ of the allowed gold partition is accepted by being multiplied by 1.4. The coefficients for each subsequent $5 \%$ increase are $1.5,2$ and 2.5 , respectively. 
have the option of leaving the cheaper funded capital to the CBRT to boost their profitability.

The CBRT defines the ROM as an automatic stabilizer: banks' decisions to keep their TL reserve requirements as foreign exchange or gold depend on funding costs, i.e. interest rates. When the ROM was introduced in September 2011, its coefficients (ROC) were low and have adjusted over time. ${ }^{8}$ Thus, we may not have enough observations for the period that ROM usage was stable and changed at the discretion of the banking system to assess its reservoir role. Importantly, the purpose of this article is not to assess whether the ROM is an effective reservoir during capital outflows but to determine whether it plays a cousin role in suppressing the effect of capital flows on economic performance. ${ }^{9}$ Therefore, when capital inflow is high, the decrease in foreign currency interest rates encourages banks to keep the required reserves in foreign currency rather than in TL, which steers incoming foreign capital to the CBRT rather than converting these foreign-currency-denominated capital flows into domestic currency. In this way, domestic liquidity is increased and thus domestic demand less to contributing financial stability. ${ }^{10}$

The CBRT thus utilizes the ROM to allow the financial market to stabilize exchange rate volatility (from abundant but disordered capital inflows) on its own as much as possible. To regulate the domestic credit line, the CBRT also expects the ROM to be effective on foreign exchange, and thus on TL liquidity. ${ }^{11}$

In order to assess how the introduction of the ROM affects the relationship between capital flow and economic performance, we provide a set of descriptive analyses. Figure 1 reports these analyses. Figure 1(a) reports the depreciation rate of the TL against the USD. Figure 1(b) reports the moving SD of exchange rate through the windows of 12 observations. Figure 1(b) suggests reducing the SD of the USD exchange rate (depreciation) after the introduction of the ROM in September 2011. The remaining figures report the estimated coefficients of the rolling regression exchange rate, interest rate, industrial production and prices (inflation) on two measures of capital flow (current account and gross portfolio investment). Here we use the 12 observations as a sliding window for all the variables except interest rate. When we use interest rate as a regressor, we use 18 observations for the sliding window because, especially for the period prior to the ROM's introduction, interest rate was constant and the estimated parameters were unstable. Last, to see the effect of capital flow decreases, we report the absolute value of the estimated parameters. At the early stages of the estimated coefficients, the signs of the coefficients were parallel with what the economic theory suggests. Figure 1(c)-(j) clearly suggests that after the introduction of the ROM the effect of capital flows on exchange rate and interest rate decreases, but we could not see a similar pattern for industrial production or prices.

In this article, we test the effectiveness of the ROM policy by using an interactive vector autoregression (IVAR) model. We present our methodology and data in Sections II and III, respectively, discuss the empirical evidence in Section IV and lay out our conclusions in Section V.

\section{Methodology}

In order to capture the effect of capital flow on economic performance, we employ a VAR model.

\footnotetext{
${ }^{8}$ Note that the deposit interest rate for domestic currency is relative to the foreign-currency-denominated deposit rate. Thus, the CBRT has the incentive to increase ROM usage as ROC-adjusted ROM usage increases.

${ }^{9}$ The ROM is a derivative tool set-up under the reserve requirement policy. Therefore, by its nature, it might well be defined as part of the reservoir function of the reserve requirement policy. However, when introduced, it was clearly stated that its aim is to meet the TL liquidity requirements of the banking sector in a timely, controlled and efficient manner under financial turmoil while building up the CBRT's foreign exchange reserves (see the CBRT's Press Release No. 2011-35 on Required Reserves, Rediscount Credit Implementations and Foreign Exchange Selling Auctions.) Referring to this explanation, the ROM should be regarded as a tap attached to the required reserves. If this definition is true, the research should concentrate on the effectiveness of this tap function by seeking an answer to the question of whether it works to decrease the impact of capital flow volatility on the CBRT's balance sheet, rather than focusing on whether the reserve requirement's reservoir function works as a whole (see CBRT Economic Notes No. 2012-28/22, October 2012, pp. 8-10, for a simple example of a balance sheet analysis of the ROM function).

${ }^{10}$ See Alper et al. (2012) and Küçüksaraç and Özel (2012), respectively, for more information on how the ROM works and for an analytical exercise regarding how it affects economic performance.

${ }^{11}$ Oduncu et al. (2013) show that credit growth volatility diminished after the CBRT adopted the ROM.
} 


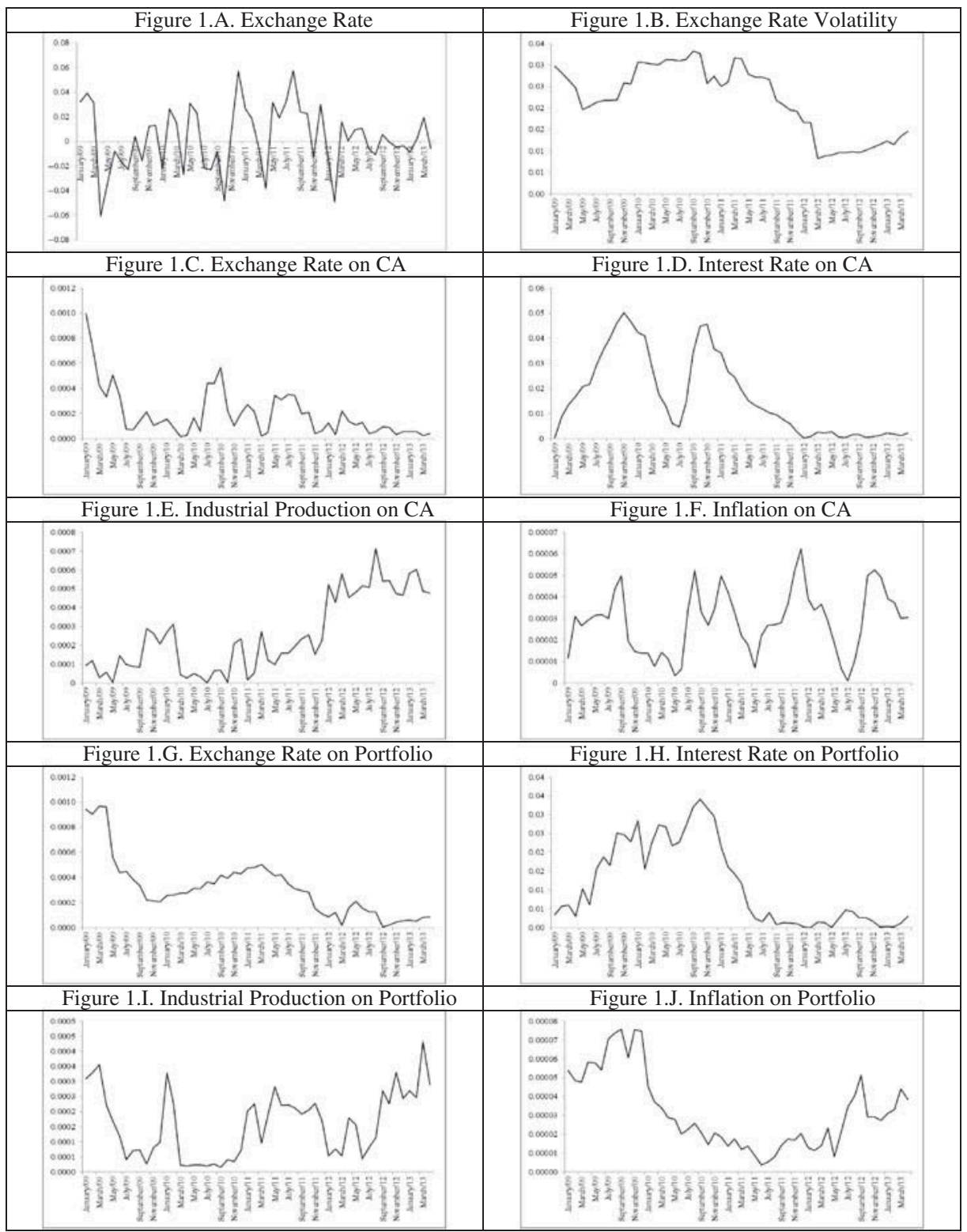

Fig. 1. Exchange rate and interest rate pass-through to capital flows

We then use impulse response analyses to assess how capital flows will affect the relevant variable, such as interest rate, exchange rate and output over time. The purpose of this article is to show that since the ROM's introduction, and at different levels of the ROM, its usage by commercial banks will change. In other words, the coefficients of the VAR specifications change with the use of the ROM as well as at different levels of ROM usage. We effectively use two samples: one for the period when the ROM was zero (i.e. when it was not employed) and the other when the ROM was not zero but changing. We capture how the effect of capital flows on economic performance changes with the ROM by using the interactive term. To assess the effectiveness of the ROM on curving capital flows, we use an IVAR similar to Tobwin and Weber's (2011a) and Saborowski and Weber's (2013) interacted panel VAR (IPVAR). We modify the IPVAR slightly to apply it to our time-series data, with the resulting specification written as follows:

$A_{0} Y_{t}=C+\sum_{k=1}^{L} A_{k} Y_{t-k}+C X_{t}+\sum_{k=1}^{L} B_{k} X_{t} Y_{t-k}+u_{t}$

where $t=1,2, \cdots, T$ 
$Y$ is a $q \times 1$ vector of explanatory variables, $A_{k}$ and $B_{k}$ are a $q \times q$ matrix of coefficients and $u_{t}$ stands for the uncorrelated iid residual terms. The necessary condition for the model is that the variables should be integrated in order zero. $L$ is the lag order. $X_{t}$ is the interaction term, scalar for each $t$, which stands for the dynamic relationship among the endogenous variables. The interaction term is also allowed to affect the intercept term. Here, we have $A_{0}$ as a lower triangular matrix, and thus we identify the shocks through the Cholesky decomposition.

The above equation can therefore be written as

$$
A_{0} Y_{t}=C\left(I+X_{t} I_{t}\right)+\sum_{k=1}^{L}\left(A_{k}+B_{k} X_{t}\right) Y_{t-k}+u_{t}
$$

To assess the effect of capital flows on the macroeconomic variables, we estimate the following recursive IVAR model:

\section{Data}

We use monthly data from January 1992 to June 2013 to construct an IVAR model with five variables: capital flow, exchange rate, interest rate, industrial production and prices. The Appendix provides the definitions and sources of the variables. We took the logarithmic first differences of USD, Ip and Cpi to satisfy the stationarity condition of the IVAR specification, as discussed by Towbin and Weber (2011b, p. 17). Although logarithmic differencing may not capture the effects of high inflation and currency depreciation, using a stationary series is one of the required properties of the IVAR method. In order to eliminate the adverse effect of this method, we report the accumulated impulse responses rather than the impulse responses on levels. All data are gathered from the CBRT's electronic data delivery system except for the ROM data, which are gathered from the CBRT's July 2013 inflation report.

$$
\left(\begin{array}{ccccc}
1 & 0 & 0 & 0 & 0 \\
\alpha_{0}^{21} & 1 & 0 & 0 & 0 \\
\alpha_{0}^{31} & \alpha_{0}^{32} & 1 & 0 & 0 \\
\alpha_{0}^{41} & \alpha_{0}^{42} & \alpha_{0}^{43} & 1 & 0 \\
\alpha_{0}^{51} & \alpha_{0}^{52} & \alpha_{0}^{53} & \alpha_{0}^{54} & 1
\end{array}\right)\left(\begin{array}{c}
\text { Cap.flow }_{t} \\
\text { Exchange }_{t} \\
\text { Interest }_{t} \\
\text { Output }_{t} \\
\text { Prices }_{t}
\end{array}\right)=\mu_{t}+\sum_{l=1}^{L}\left(\begin{array}{ccccc}
\alpha_{l, t}^{11} & \alpha_{l, t}^{12} & \alpha_{l, t}^{13} & \alpha_{l, t}^{14} & \alpha_{l, t}^{15} \\
\alpha_{l, t}^{21} & \alpha_{l, t}^{22} & \alpha_{l, t}^{23} & \alpha_{l, t}^{24} & \alpha_{l, t}^{25} \\
\alpha_{l, t}^{31} & \alpha_{l, t}^{32} & \alpha_{l, t}^{33} & \alpha_{l, t}^{34} & \alpha_{l, t}^{35} \\
\alpha_{l, t}^{41} & \alpha_{l, t}^{42} & \alpha_{l, t}^{43} & \alpha_{l, t}^{44} & \alpha_{l, t}^{45} \\
\alpha_{l, t}^{51} & \alpha_{l, t}^{52} & \alpha_{l, t}^{53} & \alpha_{l, t}^{54} & \alpha_{l, t}^{55}
\end{array}\right)\left(\begin{array}{c}
\text { Cap.flow }_{t-1} \\
\text { Exchange }_{t-1} \\
\text { Interest }_{t-1} \\
\text { Output }_{t-1} \\
\text { Prices }_{t-1}
\end{array}\right)+u_{t}
$$

where Cap.flow is the volume of capital inflows relative to GDP, Exchange is the TL equivalent of USD, Interest is the CBRT's funding rate, Output is the value of production, Prices is consumer prices, $u_{t}$ is the iid uncorrelated error term and $\mu_{t}$ is the vector for the constant term. We include 11 monthly dummies to account for seasonality, and also include crisis dummy variables for 1994:04, 1994:05, 2000:11, 2001:02 and 2001:03. The critical assumption here is that $\alpha_{l, t}^{j k}$ $\mathrm{s}$ are left to systematically vary according to a rule, depending on the ROR and ROC defined by the ROM:

$$
\alpha_{l, t}^{j k}=\beta_{l, 1}^{j k}+\beta_{l, 2}^{j k} \operatorname{rom}_{t}
$$

Here, $\operatorname{rom}_{t}$ is the percentage change in reserve options that is used by the banking sector relative to central bank reserves.
The ROM was introduced in September 2011, thus only data after this date are available and can be reported. Figure 2 reports the percentage change in reserve options that is used by the banking sector relative to central bank reserves. For our sample, we have 22 observations, where the ROM average is 0.043056 and its SE is 0.019922 .

In the model, capital flows are represented by two highly sensitive macro variables: current account deficit $(C A)$ and gross portfolio investments (Portfolio) in USD. The former is one of the easiest variables to observe and one of the most important macro variables regarding the Turkish economy's vulnerability. The latter is one of the most volatile variables in balance-of-payment statistics. Therefore, for comparison and accuracy, we estimate the model twice, once using current account deficit and once using gross portfolio investments, to represent capital flows. Because we use the lagged value of the denominator, both of these variables enter to the 


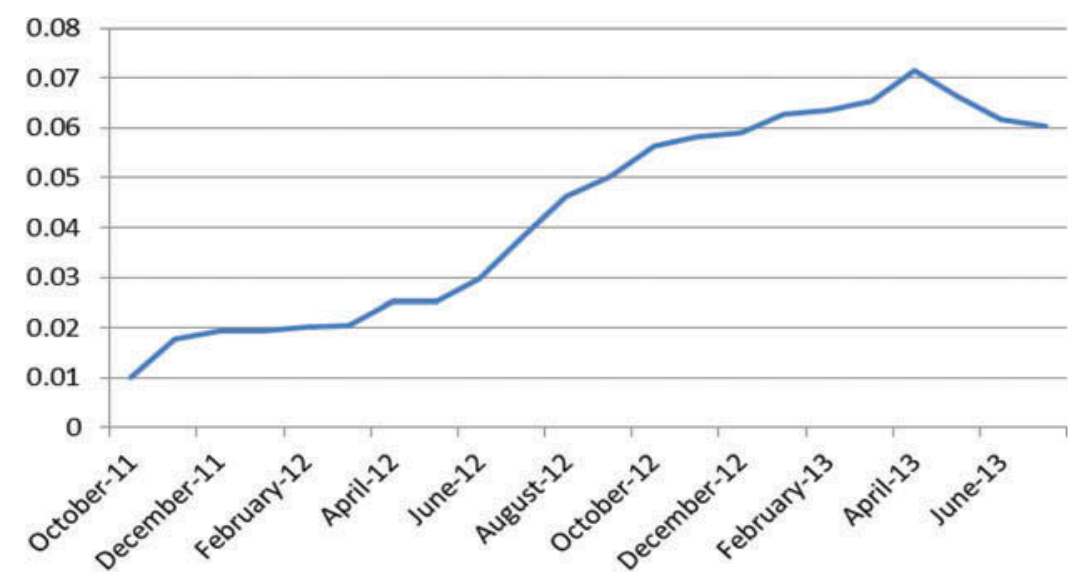

Fig. 2. Graph of the rom (October 2011-January 2015)

Source: CBRT and own calculations.

specification in their ratio to the lagged values of interpolated monthly GDP in USD to avoid simultaneity.

Although we take overnight interest rate as the interest rate (Int) until August 2010, thereafter, following the shift in funding policy, we use the monetary policy interest rate. We use rom $_{t}$ to capture the effect of the ROM. The data are used as the change in ROM usage in terms of foreign exchange and gold to the central bank's gross domestic reserves.

\section{Empirical Evidence}

Figure 3 reports the conventional cumulative impulse responses of capital flow, exchange rate, interest rate, output and prices for 18 months when a 1 SD shock is given to capital flow, and where capital flow is measured with the current account deficit. Thus, we gather the cumulative impulse responses when the ROM effect is not present or when $\operatorname{rom}_{t}=0$. The middle line shows the impulse responses and the other two lines show the
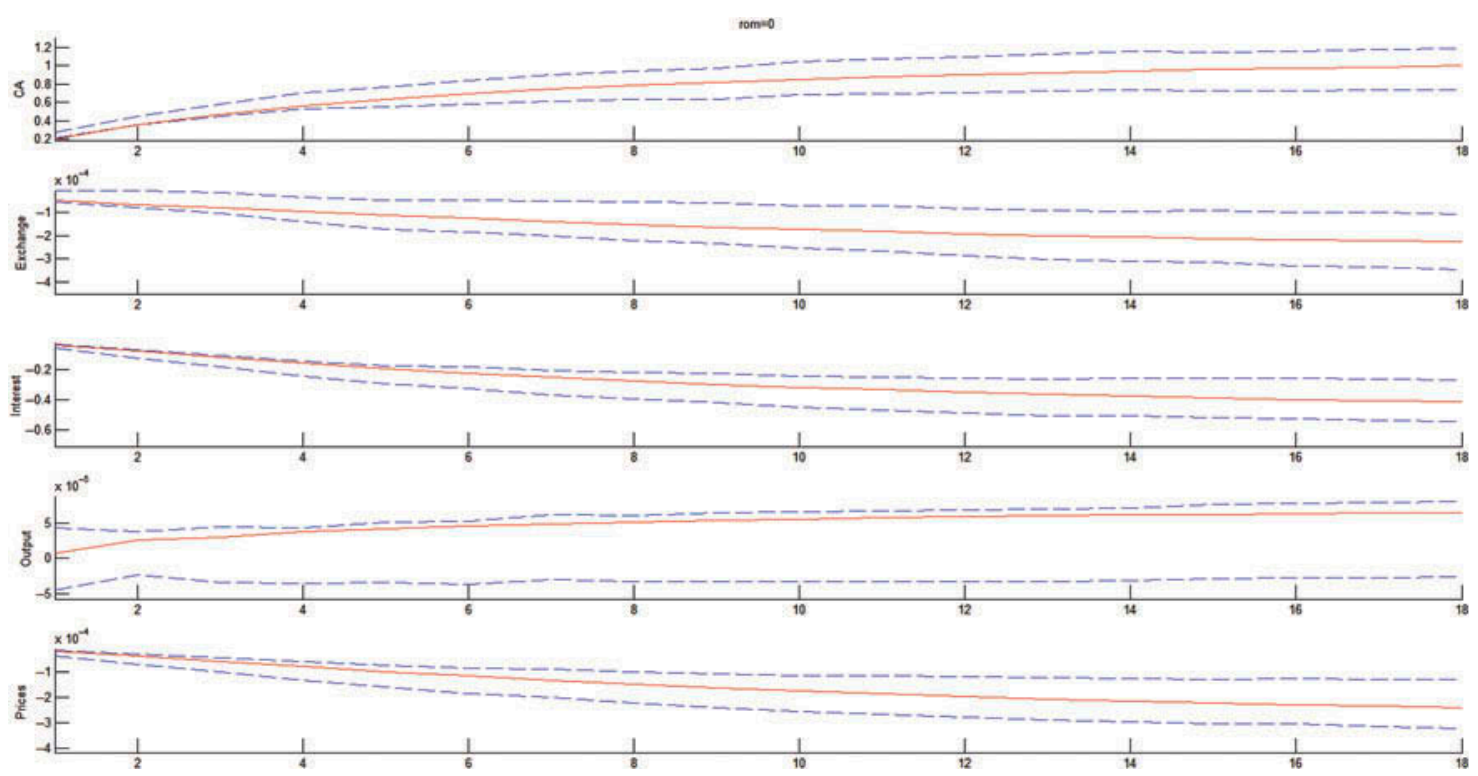

Fig. 3. Impulse responses to capital flow (current account) shock with no-ROM 
confidence intervals of the $1 \mathrm{SD}$. To calculate the confidence bands, we use Towbin and Weber's (2011a) bootstrap procedure with 1000 draws. The cumulative impulse responses suggest that the shock to capital flow is persistent, and it immediately decreases exchange rate (appreciation of local currency), interest rates and prices, but increases
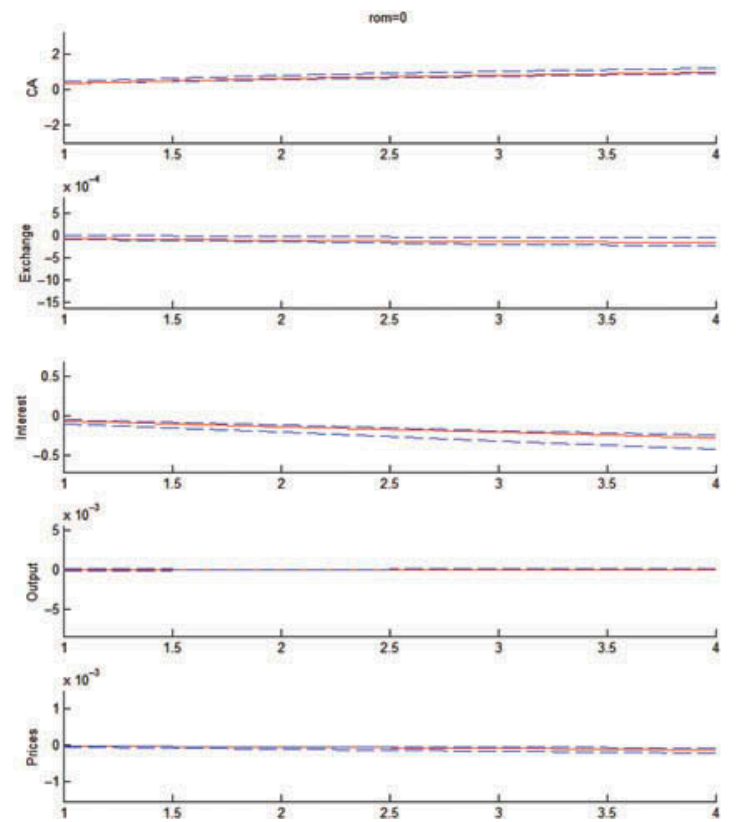

Fig. 4. Impulse responses to capital flow (current account) shock when ROM is at the 0 and 75 th percentiles for four periods
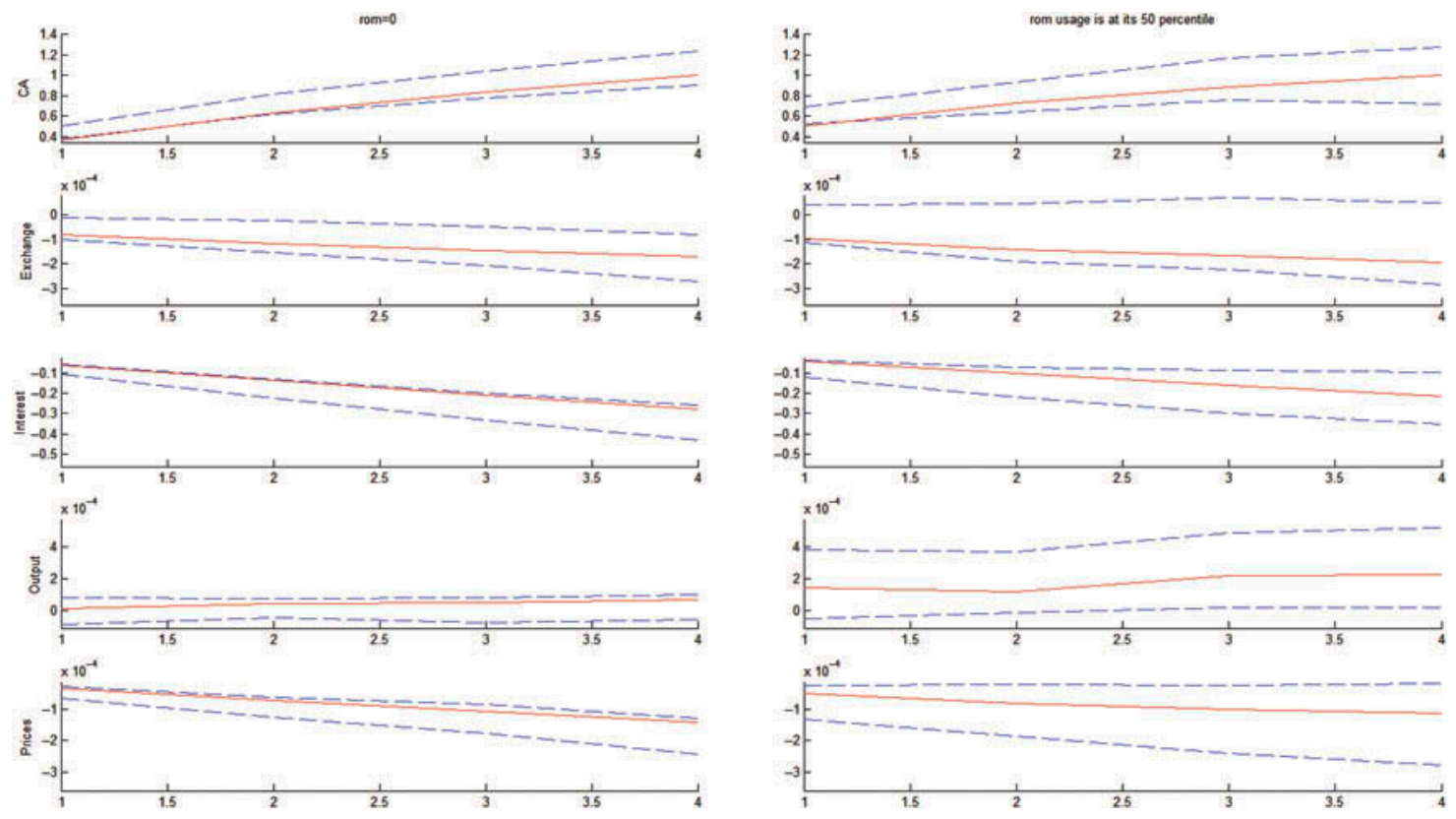

Fig. 5. Impulse responses to capital flow (current account) shock when ROM is at the 0 and 50th percentiles for four periods

output in a persistent manner. These results are parallel with Berument and Dincer (2004) for Turkey. Only the effect of capital flow shock on output is not statistically significant.

Next, we compare the two impulse responses. In Figs 4-10, the impulse responses in the first column are produced by taking ROM usage as zero. These are
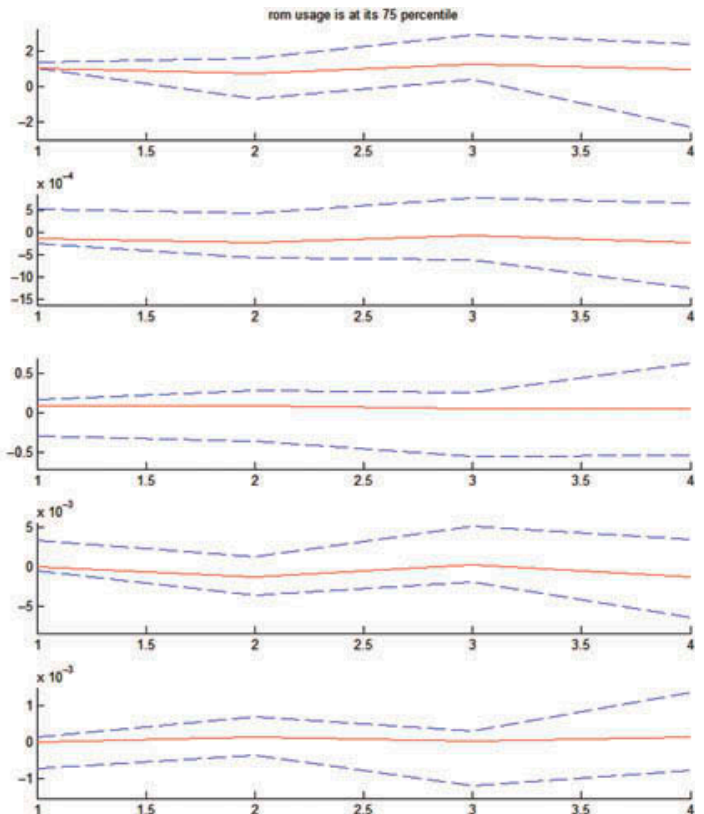

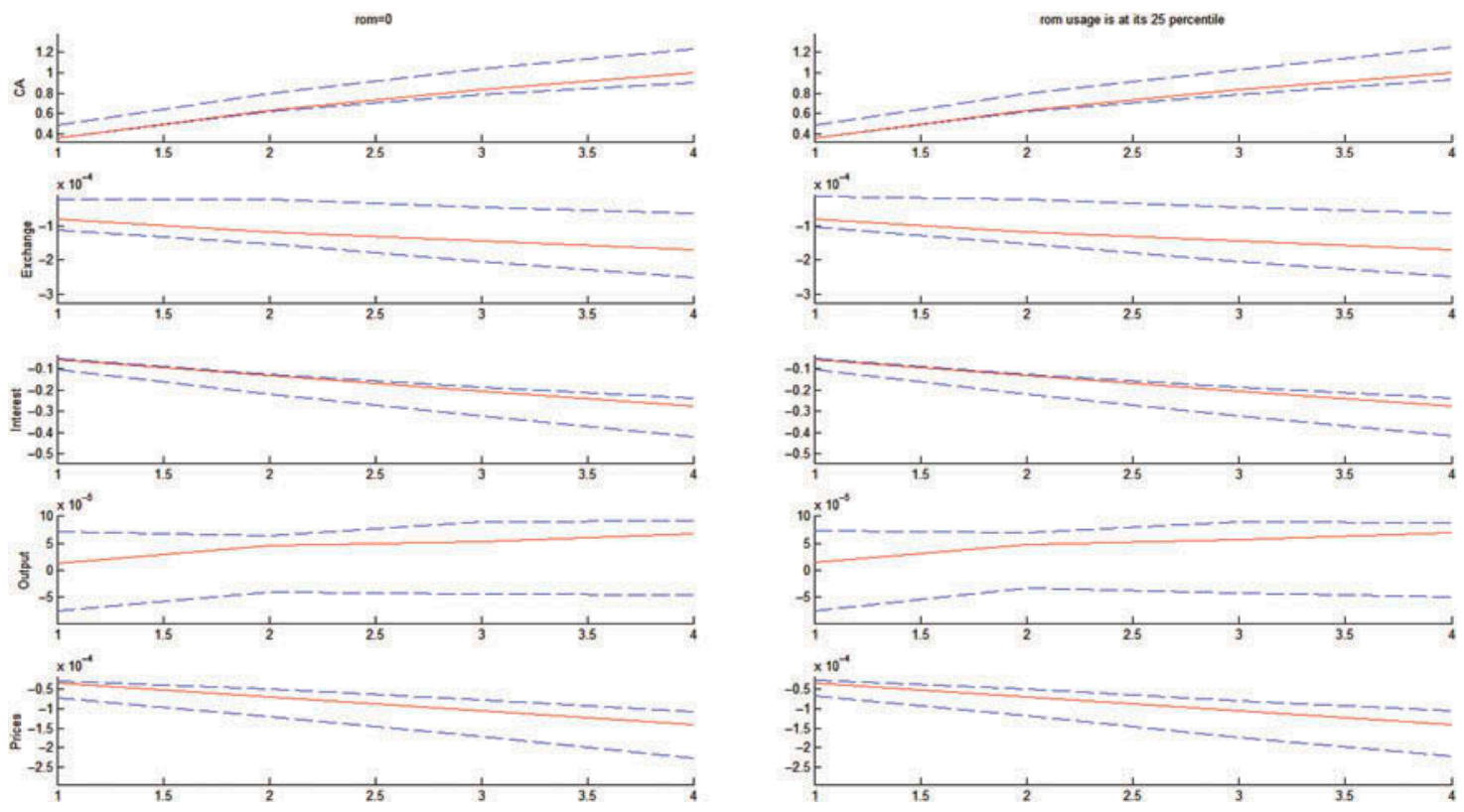

Fig. 6. Impulse responses to capital flow (current account) shock when ROM is at the 0 and 25 th percentiles for four periods
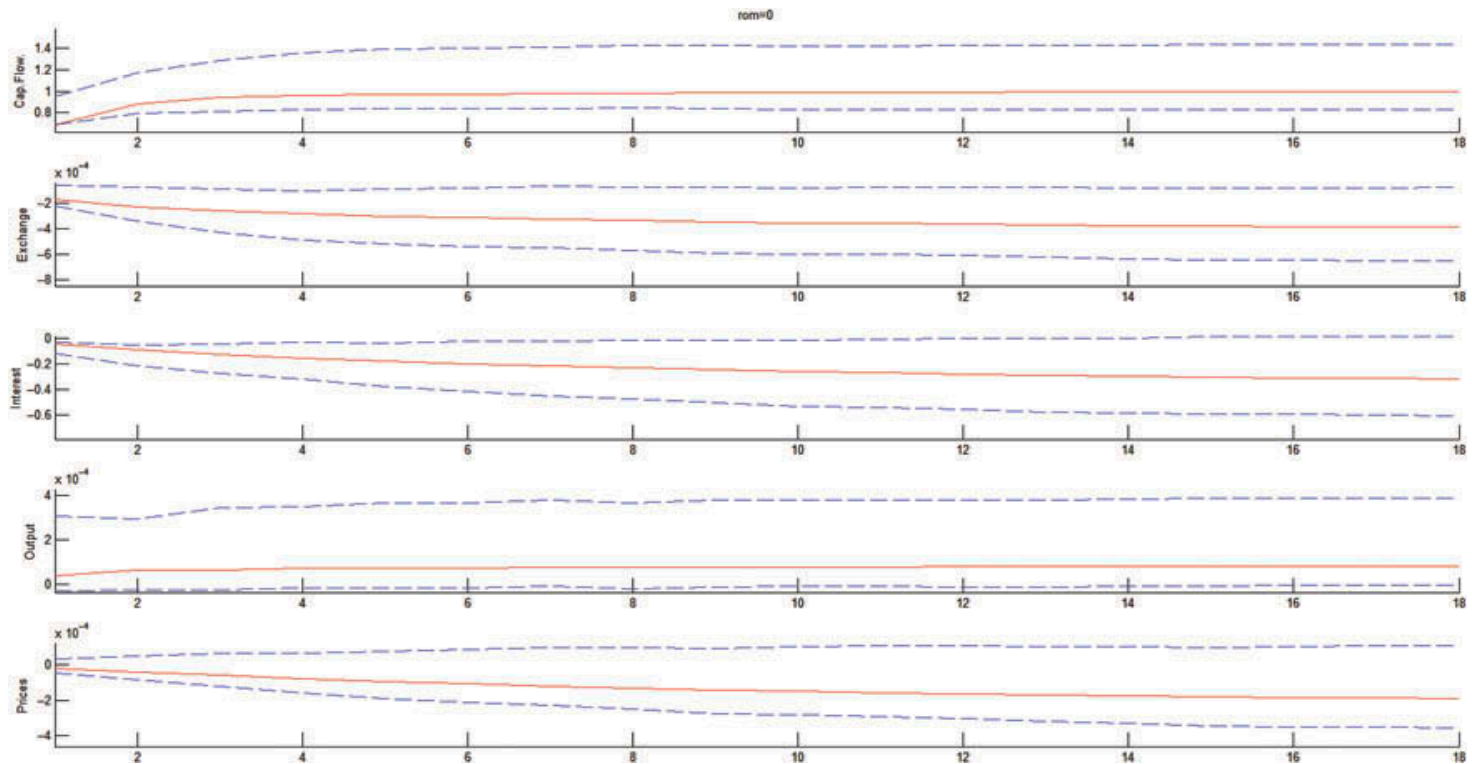

Fig. 7. Impulse responses to capital flow (gross portfolio flow) shock with no-ROM

the same impulse responses as in Fig. 3. However, when comparing columns of Figs $4-10$, we see that the scales of the first columns are different. In the second column of Fig. 4, ROM usage is equal to its 75th percentile (of the historical data after September 2011). We report impulse responses for four periods to make the comparison more visible under different ROM usages. The second column suggests that the shock to the current account deficit is not persistent. After 1.5 periods, the effect of capital flow on capital flow dies out. For the remaining impulse responses, the effects are not statistically significant. Thus, the effect of capital flows could be eliminated if the ROM growth rate is set to its 75 th percentile.

Figure 5 repeats the same comparison by setting the ROM growth rate to its 50th percentile in the 

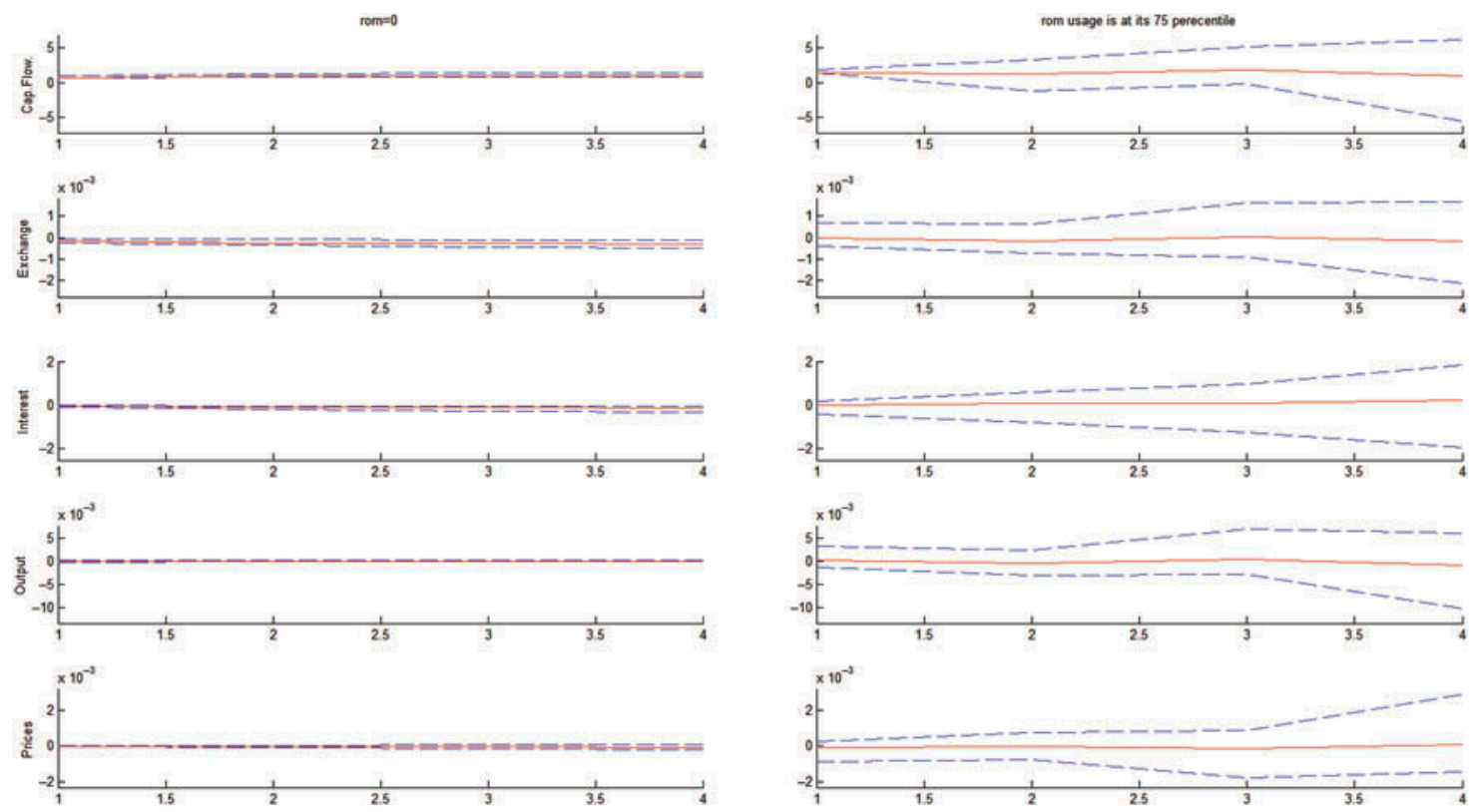

Fig. 8. Impulse responses to capital flow (gross portfolio flow) shock when ROM is at the 0 and 75 percentiles for four periods
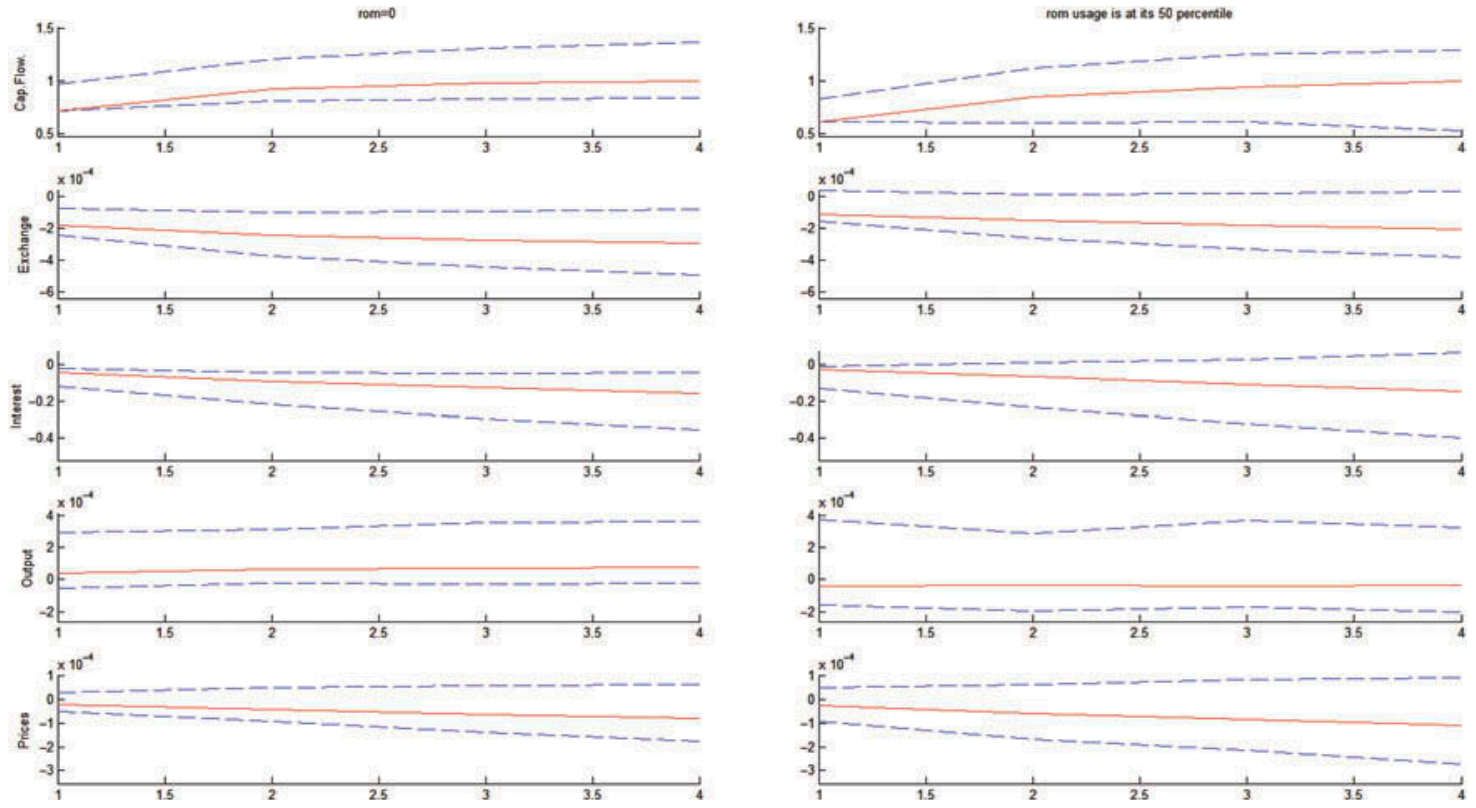

Fig. 9. Impulse response to capital flow (gross portfolio flow) shock when ROM is at the 0 and 50 th percentiles for four periods

second column, while the first column remains zero, as in Fig. 2. In this instance, ROM growth rate is $0 \%$. Here, current account shocks persist and the decreases in interest rate and prices are still statistically significant. The effects on exchange rate and output are not statistically significant.
Figure 6 compares the impulse responses on the same variables by taking ROM growth as the 25th percentile in the second column. Virtually, there is no difference between the first two columns; they exhibit responses of no-ROM and 25th percentile increases in ROM situations, respectively. Therefore, we cannot 

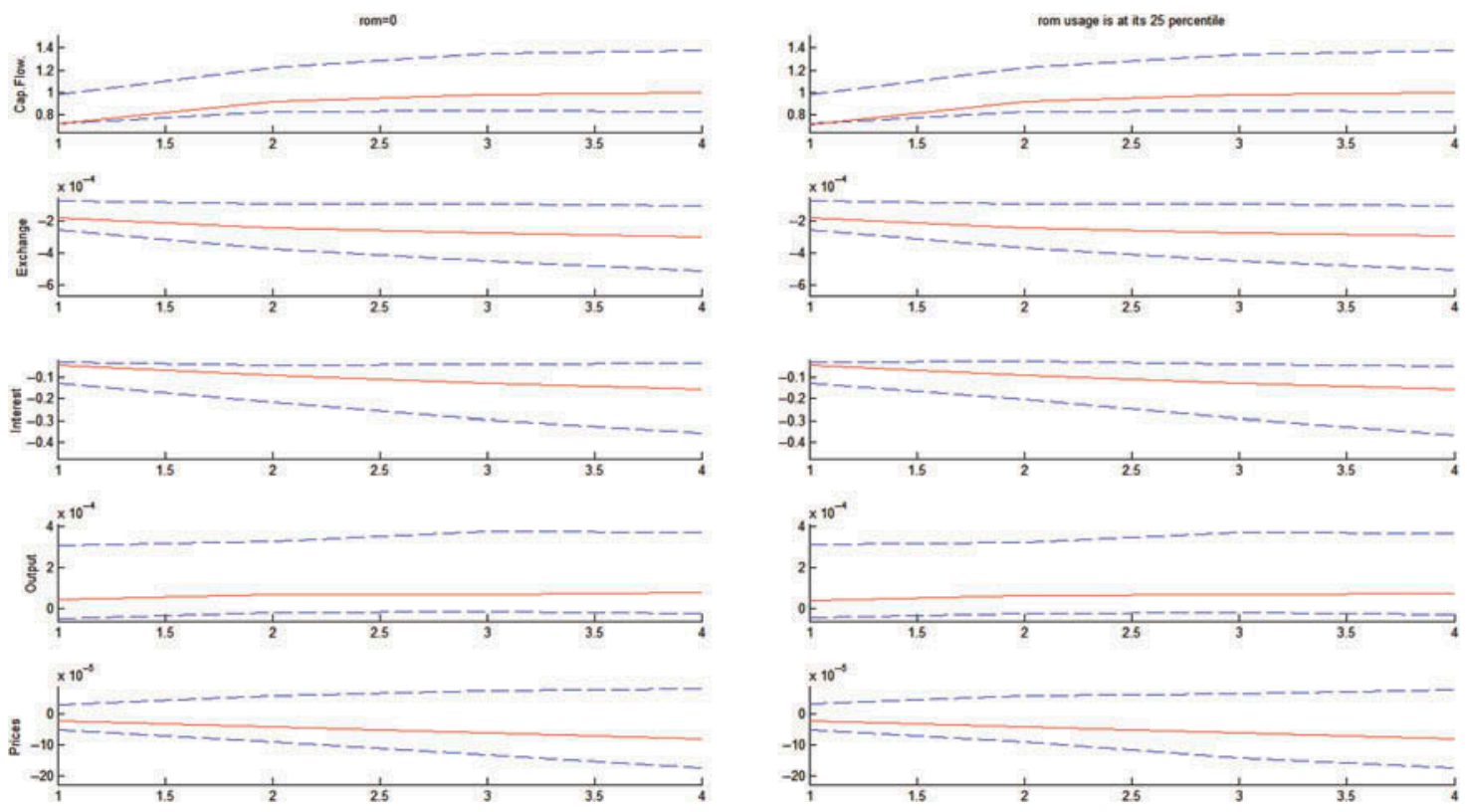

Fig. 10. Impulse response to capital flow (gross portfolio flow) shock when ROM is at the 0 and 25 th percentiles for four periods

claim that the effect of capital flows could be eliminated by increasing the ROM this much. This result clearly suggests that as long as the CBRT ensures the ROM growth rate is high enough it could decrease the effect of capital flow. However, the sustainability of this constrained policy option is debatable.

Figures 7-10 report the same exercises as Figs 3-6, but mimic capital flows with gross portfolio flows (i.e. a shock is given to gross portfolio capital flows). For normalization, we also take the lag value of the USD value of the interpolated monthly GDP. Gross capital flows are important because they are one of the main sources of current account deficit financing (Başç1, 2013a) and are positively sensitive to income growth (Baş̧̧1, 2013b). However, the volatility of capital flows may increase Turkey's misalignment problems in currency and credit (Başç1, 2013c).

Figure 7 suggests that a 1 SD shock permanently increases capital flow for 18 months, appreciates local currency and decreases interest rates. The effects on output and prices are positive and negative, respectively, as expected, but these results are not statistically significant.

Figure 8 suggests that when the ROM growth rate is set at the 75th percentile the effect of capital flow on capital flow is not persistent. Although persistent, the effects of the shock on exchange rate, interest rate, output and prices are not statistically significant. These results are parallel with the above specification, which employs current account to measure capital flows.

Figures 9 and 10 repeat the exercise by setting ROM growth rates at the 50th and 25th percentiles, respectively. In the former, capital flow is still persistent (as in the no-ROM situation) but the effects of the capital flow shock on exchange rate, interest rate, output and prices are not statistically significant, similar to the ROM growth rate in the 75 th percentile. In the latter, the impulse responses of the connected variables are similar to when the ROM growth rate was set to the zero percentile.

\section{Conclusions}

Central banks developed innovative tools to cope with the new challenges in the post-2008 financial market. Keeping price stability as its main policy target, the CBRT considered financial stability a complementary target and employed a new set of tools, including the ROM, to achieve both of the targets. In the face of capital flow shocks, the CBRT aims to decrease the effect of capital flows on economic performance such that part of this flow may go to the CBRT to increase its reserves rather than go to financial markets directly. Thus, the CBRT developed an incentive mechanism for commercial banks such that they may substitute part of their 
local-currency-denominated liabilities with their foreign exchange reserves or with gold. Thus, currency appreciation will be lower at a given level of capital flows at a higher level of the ROM. The effect of capital flows on interest rate, output and prices will be lower at a higher usage of the ROM for a given change in capital flows as well.

In other words, this article assesses whether the ROM plays a cousin role against capital flows. To be particular, we test whether the effect of capital flows on macroeconomic performance has changed with the introduction of and changes with higher levels of ROM usage. The empirical evidence gathered from Turkey suggests that the introduction of the ROM, as well as its higher usages, decreases the effect of capital flow to itself (less persistent). Moreover, the effects of capital flow on interest rate and exchange rate also decrease with a higher ROM usage. Thus, the existence of the ROM might be used as one tool the central banks of small open economies may use to decrease the effect of capital flow on financial markets.

\section{Acknowledgement}

The authors would like to thank Sebastian Weber for sharing his MATLAB codes and Rana Nelson for her helpful comments.

\section{Disclosure Statement}

No potential conflict of interest was reported by the authors.

\section{References}

Alper, K., Kara, H. and Yörükoğlu, M. (2012) Reserve options mechanism, CBRT Economic Notes, No: 2012-28, CBRT, Ankara.

Başçı, E. and Kara, H. (2011) Finansal İstikrar ve Para Politikası (Financial Stability and Monetary Policy), CBRT Working Paper No. 11/08, CBRT, Ankara.

Başçı, E. (2013a) Does international inter-dependence imply more policy cooperation necessarily, in Presentation at the Modelling International Linkages and Spillovers, CBRT-ECB Joint Conference, Izmir, 3 October.

Başç1, E. (2013b) IMF-World Bank spring meetings, in Presentation at the Central Bank of the Republic of Turkey, April 2013.
Başç1, E. (2013c) Economic outlook in Turkey, in Presentation at London, CBRT, London.

Berument, H. and Dincer, N. (2004) Do capital flows improve macroeconomic performance in emerging markets? The Turkish experience, Emerging Markets Finance and Trade, 40, 20-32.

Blanchard, O., Dell'Ariccia, A. and Mauro, P. (2013) Rethinking macro policy II: getting granular, in IMF Research Department Staff Discussion Note, SDN/13/03.

CBRT (2011) Press release on required reserves, rediscount credit implementations and foreign exchange selling auctions, in Central Bank of the Republic of Turkey Press Release, No. 2011-35, CBRT, Ankara, pp. 1-2 (12 September 2011).

CBRT (2013) Inflation Report III, Central Bank of the Republic of Turkey, Ankara. Available at: http:// www.tcmb.gov.tr/research/parapoli/inflation 2013 III_full.pdf.

Cerutti, E., Claessens, S. and Laeven, L. (2015) The use and effectiveness of macroprudential policies: new evidence, IMF Working Paper, WP/15/61.

Claessens, S., Ghosh, S. T. and Mihet, R. (2014) Macroprudential policies to mitigate financial system vulnerabilities, IMF Working Paper, WP/14/155.

Claessens, S. (2014) An overview of macroprudential policy tools, IMF Working Paper, WP/14/214.

Clerc, L., Derviz, A., Mendicino, C. et al. (2014) Macroprudential capital tools: assessing their rationale and effectiveness, Banque de France Financial Stability Review No. 18, Banque de France, Paris, pp. 183-93.

Galati, G. and Moessner, R. (2014) What do we know about the effects of macroprudential policy?, DNB Working Papers 440, Netherlands Central Bank, Research Department, Amsterdam.

IMF (2011) Macroprudential policy: an organizing framework, in Prepared by the Monetary and Capital Markets Department in Consultation with Research and Other Departments, IMF, Washington, DC.

Kara, H. (2012) Monetary policy in Turkey after the global crisis (Kuresel Kriz Sonrasi Para Politikasi), Iktisat, Işletme Ve Finans, 27, 9-35.

Küçüksaraç and Özel, (2012) "Rezerve Opsiyon Mekanızması ve OptimalReserve Opsiyonu Katsayılarının Hesaplanması" (Reserve Option Mechanism and Optimal Reserve Coefficient Calculations), mimeo.

Oduncu, A., Ermişoğlu, E. and Polat, T. (2013) The effect of CBRT's new policy mix on the volatility of credit growth, CBT Research Notes in Economics, 27, 1-11.

Saborowski, C. and Weber, S. (2013) Assessing the determinants of interest rate on transmission through conditional impulse response functions, International Monetary Fund Working Paper No. 13/23, IMF, Washington, DC, pp. 1-36. 
Towbin, P. and Weber, S. (2011a) Limits to floating exchange rates: the role of foreign currency debt and import structure, International Monetary Fund Working Paper, No. 11/42: 1-51.

Towbin, P. and Weber, S. (2011b) A Guide to the Matlab Toolbox for Interacted Panel VAR estimations (IPVAR), 1-17. (December).
Yorukoglu, M. and Cufadar, A. (2008) Capital flows to Turkey: financial implications and policy responses, BIS Papers on Financial Globalization and Emerging Market Capital Flows, No. 44, 467-84.

Zhang, L. and Zoli, E. (2014) Leaning against the wind: macroprudential policy in Asia, IMF Working Paper, WP/14/22, IMF, Washington, DC.

\section{Appendix: Data sources}

\begin{tabular}{|c|c|c|c|}
\hline Variable & Definition & Code & Source \\
\hline$G D P$ & Real GDP & TP.UR.G23 & CBRT, EDDS \\
\hline Int & $\begin{array}{l}\text { Simple interest rate weighted average (\%) (overnight)+ } \\
1 \text {-week repo + weighted funding interest rate. After } 3 \\
\text { October } 2011 \text {, we used the CBRT weighted average } \\
\text { funding cost }\end{array}$ & TP.PY.P06.ON & CBRT, EDDS \\
\hline Output & Industrial production $(1992=100)$ & TP.UR4.U01 & CBRT, EDDS \\
\hline $\mathrm{Cpi}$ & $\begin{array}{l}\text { General index, consumer }(1987=100, \text { general price index } \\
\quad(\text { consumer price })(2003=100)\end{array}$ & $\begin{array}{l}\text { TP.FG.A01 } \\
\text { TP.FG.J0: } 0\end{array}$ & CBRT, EDDS \\
\hline Portfolio & $\begin{array}{l}\text { Gross portfolio investment, balance of payments detailed } \\
\text { presentation, monthly, million USD }\end{array}$ & TP.OD.Q099: II-B2 & CBRT, EDDS \\
\hline$R O M$ & $\begin{array}{l}\text { TL required reserves held at CBRT as foreign currency and } \\
\text { gold, billion USD }\end{array}$ & CBRT (2013) & CBRT $(2013$, p. 82) \\
\hline$C A$ & $\begin{array}{l}\text { Current account, balance of payments detailed presentation, } \\
\text { monthly, million USD }\end{array}$ & TP.OD.Q001:I & CBRT, EDDS \\
\hline USD & USD/TRY exchange rate, selling prices & TP.DK.USD.S.YTL.1 & CBRT, EDDS \\
\hline
\end{tabular}

